\title{
Pediatric death audit with special emphasis on autopsy at the University of Uyo Teaching Hospital, Uyo, Nigeria: a 6-year review
}

\author{
IJEZIE, Echey ${ }^{1}$, OKPOKOWURUK, Frances Sam², NWAFOR, Chukwuemeka Charles ${ }^{3}$ \\ ${ }^{1}$ IJEZIE, Echey, MBBS, MWACP, FMCPaed, Department of Paediatrics, ${ }^{2}$ OKPOKOWURUK, Frances Sam, MBBS, \\ FMCPaed., Department of Paediatrics, ${ }^{3}$ NWAFOR, Chukwuemeka Charles, MBBS, FMCPath, DFHID, Department of \\ Pathology. All are affiliated with the University of Uyo Teaching Hospital [UUTH], P.M.B 1136, Uyo, Akwa Ibom \\ State, Nigeria.
}

Address for Correspondence: IJEZIE, Echey, MBBS, MWACP, FMCPaed., Department of Paediatrics, University of Uyo Teaching Hospital [UUTH], P.M.B 1136, Uyo, Akwa Ibom State, Nigeria. Email: echeyijezie@yahoo.com; echey4@gmail.com.

\begin{abstract}
Background and Objectives: Paediatric autopsies are useful in the establishment of diagnosis, quality assurance and research. They are relevant in guiding genetic counseling and helping families that are grieving. Despite these uses and applications, autopsy rates have declined globally. This study was undertaken to identify the autopsy rate in the Department of Paediatrics at the University of Uyo Teaching Hospital (UUTH), Uyo, Nigeria. Materials and Methods: The current report is a descriptive, cross-sectional and retrospective review of all the deaths among the hospitalized children from 1st January 2009 to 31st December 2014. Relevant information was extracted from case files of all inpatient deaths during the period under review. Results: A total of 772 paediatric deaths were recorded during the period under review, of which $453(58.7 \%)$ were males and $319(41.3 \%)$ were females. Two hundred and twelve [212 (37.5\%)] deaths occurred within 24 hours of admission. No autopsy was conducted (0\%) on any of the cases. Conclusion: Despite the importance, paediatric autopsies are not routinely performed in this centre, and in many others. This should not be the case. Paediatric autopsy rates can be improved by making consistent autopsy requests by the attending clinicians. Advocacy and enlightenment campaigns should be conducted at facility and community levels to educate everyone concerned about the benefits of paediatric autopsies.
\end{abstract}

Keywords: Paediatric autopsies, Autopsy, Pediatric death audit.

\section{Introduction}

Autopsy is a post mortem examination, carried out on a dead body, not only to find out the cause of death, but to discover the pathogenesis and pathophysiology of events that lead to death $[1,2]$.

Paediatric autopsies are useful in the establishment of diagnosis, quality assurance and research [3]. They are also used in guiding genetic counseling and helping families that are grieving [4]. Additionally, autopsies are important in epidemiology, for identifying risk factors and the possibilities of outbreak of disease [5]. Autopsies are therefore invaluable in improving clinical practice and, providing rational framework for decisionmaking among policy makers [6].

Manuscript received: $13^{\text {rd }}$ Oct 2015

Reviewed: $20^{\text {th }}$ Oct 2015

Author Corrected: $29^{\text {th }}$ Oct 2015

Accepted for Publication: $18^{\text {th }}$ Nov 2015
Despite these well documented uses and applications, autopsy rates have declined globally [4,7]. The reasons for this decline are varied and complex $[5,8,9]$. They include dearth of qualified personnel, inadequate resources and constraints in capacity [6], attitude among health care workers, family concerns about delays, disfigurement and, objections on religious grounds [5]. Other reasons include fear of litigation due to incorrect diagnosis (among the healthcare workers), and the cost implication of the autopsy $[8,10]$.

Another reason for the low rate of autopsy are the recent advances in modern medicine. Despite modern medical advances, nothing can validate or correct the death certificate like autopsy. Without an autopsy the cause of death can be wrong in as many as $30 \%$ of 
cases, although autopsies do not always provide the cause of death [11].

Furthermore, paediatric autopsies can provide new diagnoses or additional medical information in about $21 \%$ to $76 \%$ of cases of autopsy $[12,13]$. As aptly stated by Lundberg, "low technique autopsy trumps high technique medicine" [14].

Autopsies in adults or children can be categorized as either hospital (clinical) autopsy or coroner (forensic/medico-legal) autopsy [1]. Hospital autopsy is often performed on individuals in whom the disease causing death is known, but the course to death is not known [1].

In such cases, the purpose of the autopsy would be to determine the extent of the disease and/or the effects of therapy and the presence of any undiagnosed disease of interest that might have contributed to death. The next of kin must give permission (consent) for the autopsy and may limit the extent of the dissection [1].

Forensic (medicolegal) autopsy is ordered by the coroner or medical examiner as authorized by law with the statutory purpose of establishing the cause of death and answering other medico-legal questions.

The next of kin is not required to authorize and may not limit the extent of the autopsy [1]. The majority of childhood autopsies after death following hospital admissions are clinical or hospital autopsies.
This study was undertaken to identify the autopsy rate in the Department of Paediatrics at the University of Uyo Teaching Hospital (UUTH), Uyo, Akwa Ibom State, Nigeria with the aim of adding to the body of knowledge on this subject, and hopefully lead to an improvement in paediatric autopsy requests and rates.

\section{Materials and Methods}

The study was conducted at the Department of Paediatrics of the University of Uyo Teaching Hospital (UUTH), Uyo, Akwa Ibom State, Nigeria. The Department of Paediatrics has a Children's Emergency Unit (CHEU) with a twenty-two bed capacity, Paediatric ward with a twenty-seven bed capacity, and the Newborn Care Unit which has 43 cots and incubators. The Department has a total of 12 consultants and 21 resident doctors.

Akwa Ibom State is one of the 36 states in Nigeria and is located in the south-south geopolitical zone. The current report is a descriptive, cross-sectional and retrospective review of all the deaths among the hospitalized children from 1st January 2009 to 31st December 2014. Ethical approval was obtained from the Ethics Committee of the UUTH.

Case files of all in-patient deaths during the period under review were studied. The relevant information extracted included age, sex, date and time of admission, date and time of death, and diagnosis, evidence of autopsy request, and autopsy results. The statistical analysis was basic descriptive statistics.

\section{Results}

A total of 772 deaths were recorded during the period under review (1st January 2009 - 31st December 2014). The total number of deaths per year were 148 (year 2009), 116 (year 2010), 171 (year 2011), 169 (year 2012), 103 (year 2013 ) and 65 (year 2014).

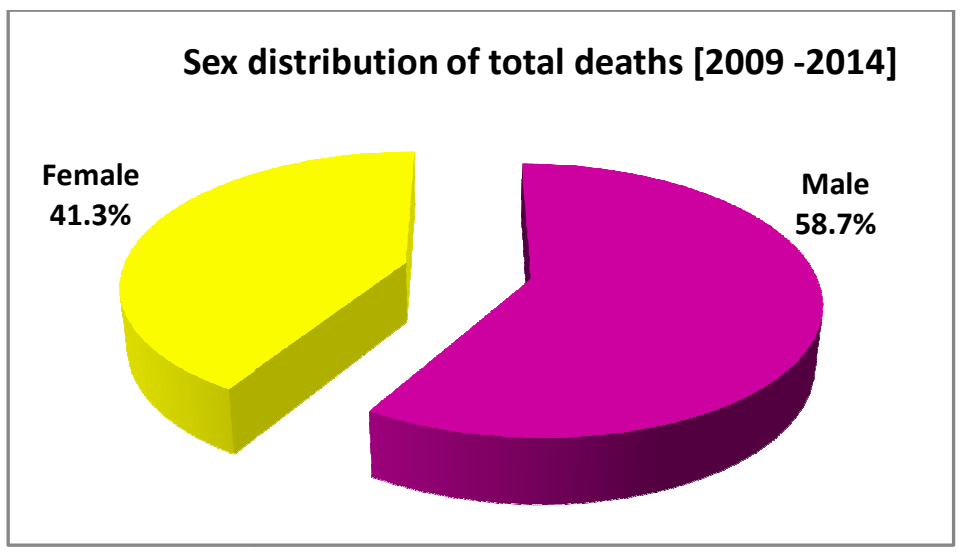

Figure 1: Sex distribution of the total deaths [2009 - 2014]: 
Records for the total number of admissions were available only for 2013 and 2014. These records show that in 2013 there were a total of 2,514 admissions, out of which there were 103 deaths (giving a death rate of $4.1 \%$ ), while in 2014 there were 2,085 admissions, out of which there were 65 deaths (giving a death rate of $3.1 \%$ ).

Of these 772 total deaths, $453(58.7 \%)$ were males and $319(41.3 \%)$, giving a male: female ratio of 1.4:1 [Figure 1].

Four hundred and thirty nine deaths (56.9\%) were among children aged less than one month, while 120 deaths (15.5\%) were among children aged 1 month - 1 year. Ninety two deaths (11.9\%) were among children aged more than 1 year - 5 years, while 121 deaths $(15.7 \%)$ were among those aged more than 5 years. The total number of deaths by age and sex is as shown in figure 2 .

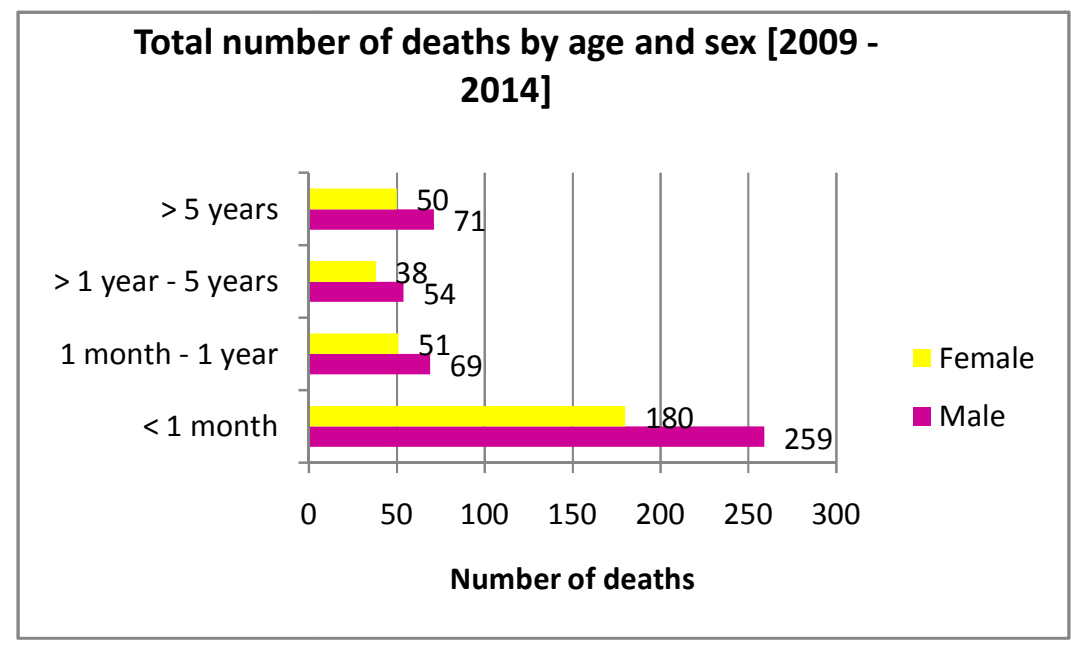

Figure 2: Total number of deaths by age and sex [2009 -2014]:

Two hundred and twelve [212 (37.5\%)] deaths occurred within 24 hours of admission, ninety one [91 (16.1\%) deaths occurred between 24-48 hours from the time of admission, while two hundred and sixty two [262 (46.4\%)] deaths occurred after 48 hours from the time of admission. [Figure 3].

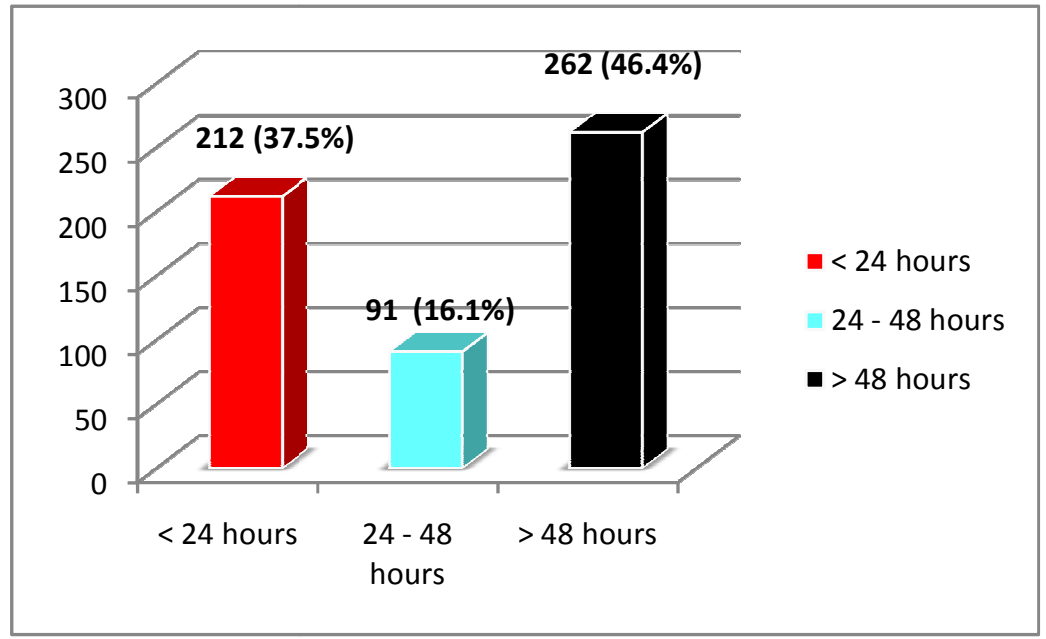

Figure 3: Duration of hospitalization before death*:

*: These were the case files that had recordings of the time of death (A total of 565).

Out of the total of 772 paediatric deaths recorded during the period under review, no autopsy was conducted $(0 \%)$.

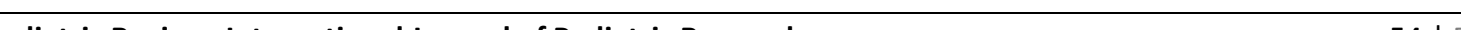




\section{Discussion}

Ideally, all paediatric cases should be submitted for postmortem examination. An autopsy rate of at least $75 \%$, especially in cases of perinatal deaths, is necessary to achieve educational, quality control, and research goals [15].

Though there is a global decline in autopsy rates, pediatric autopsy rates are not declining as fast as adult autopsy rates [16]. The overall pediatric autopsy rate in year 2000 was $40 \%$ in Salt Lake City USA [17], while in Chicago, an autopsy rate of $36 \%$ in children was reported [4].

In a study in Wales, there was a decline from a rate of $66.5 \%$ in 1994 to $47.97 \%$ in 2003 [18]. The autopsy rate for stillbirths and neonatal deaths in 2001 in Scotland was noted to have declined to $50.8 \%$ from a rate of $72.4 \%$ in 1997 [19]. Brodlie et al., in 2002 reviewed the case records of 314 neonatal deaths in Edinburgh between 1990 and 1999 [20]. They observed that autopsies were performed in $67 \%$ of cases, but the rate declined throughout the decade by an average of $2.8 \%$ per year [20]. In the United Kingdom, hospital autopsy rates in children's hospital NHS range from $0 \%$ to $21 \%$ [21].

The Chicago study made an interesting finding that autopsies were not associated with gender, race, or insurance, but significantly increased with age as high as $100 \%$ by 61 months of age or higher due to greater parental willingness to consent to autopsy based on the following reasons: longer illness course, closer relationship between the family and the treating physician and increased understanding of the importance of autopsy [4]. Studies in Ghana and Zambia reported rates of $30 \%$ and $10 \%$ respectively $[9,22,23]$

This study revealed a paediatric autopsy rate of $0 \%$ in Uyo, Nigeria. This is a matter of concern. Low paediatric autopsy rates have also been found in other studies in Nigeria. Similar findings were obtained in a study at the University of Port Harcourt Teaching Hospital, Port Harcourt, Nigeria, by Eke et al., in which there were 98 deaths $(5.1 \%)$ out of a total of 1777 admissions between January to December 2000 [24]. However, post mortem examination was performed in only one child $(0.01 \%)$ in the study [24].

Nwafor et al in Umuahia reported an autopsy rate of $0 \%$ following 3,814 admissions with a mortality rate of
$11 \%$ [25], while Ugiagbe et al [26] in Benin reported a $0.8 \%$ neonatal autopsy rate [26].

Autopsies following childhood mortality in Ibadan, Nigeria, fell from $60 \%$ of cases in 1961 to $18 \%$ in 1988 [27], while also in Ibadan, a rate of $7.4 \%$ was found for the years 1996-2000 [28]. Furthermore, in Ibadan, Oluwasola et al in their study found that the autopsy rates at the University College Hospital, had declined from an average of $19 \%$ in 1984 to $3.6 \%$ in 2003 [29]. However, a study in Lagos reported a pediatric autopsy rate of 24.8\% between 1993-1994 [30].

In some teaching hospitals in Nigeria (such as in Lagos, Ibadan, Benin and Ile-Ife), there are strict rules and policies that insist on Coroner's Law that all deaths within 24 hours, and all suspicious deaths must have postmortem examinations. This may have influenced the rate of autopsies from these centers. The high rate in Ghana may be due to the performance of autopsies without seeking the consent of families [9].

Though there was no documentation in the case files of the cases in which autopsies were requested for in our study, the plausible commonest reason for not having a single paediatric autopsy done during the period under review will be the issue of obtaining consent from the parents/guardians.

Reasons for the continuing decline in the autopsy rate are complex and multifaceted. The reasons for markedly reduced autopsy rate in the index study can be broadly divided into two. Factors related to parents/guardians/relatives and factors related to health workers (both the requesting clinicians and pathologist).

Factors related to the parents/guardians/relatives include cultural reasons (taboo to mutilate a body / dying at a young age meant a wasted life) and social reasons, while the main reason related to the health worker is the lack of will-power/conviction on the need for autopsies. These findings have been documented in various studies in other parts of Nigeria, Africa and Europe [28,31,32,33].

Other factors include complaints of time wastage before funeral; death certificate being already issued before informing the family about the need for autopsy; arrangements to transport the body may had been made and cannot be delayed [34]. Religious objection to the autopsy is another commonly encountered barrier to autopsy [35]. 
Different religions have placed different limitations on autopsy. For Judaism, an autopsy may be performed when the cause of death is undetermined, when the autopsy may help to save the lives of others, or when relatives might benefit from the knowledge gained by autopsy [35]. Catholicism and most Protestant religions accept autopsy on almost any occasion but specify that the body must be treated with respect, and the family's consent must be obtained [32]. Most Muslim leaders do not condone autopsy because of the need to bury as soon as possible after death [36], and also because the procedure may fall into the category of desecration of the dead [37]. However, the unacceptable elements of postmortems may be excused, in some quarters, on the basis of the pragmatic Islamic legal principle of 'the public benefit' (maslaha) [37].

Attitudes among health care professionals are certainly a factor in declining autopsy rates. Clinicians have tended to undervalue the clinical importance of autopsy and have become wary of requesting an examination that may reveal discrepancies between diagnosis and management and the fear of litigation [33]. Perhaps the main reason for the decline is that clinicians are not asking for consent to have an autopsy done on their patients; most times this responsibility is delegated to the most junior member of the team [31].

Many resident doctors, even chief residents, report that they have received no instructions on the autopsy procedure, obtaining consent, and the role of religious or cultural background in attitudes toward autopsy [31]. Some clinicians may not approach grieving relatives for permission for autopsy because they have their own reservations, or because they do not have confidence in their communication skills $[31,38]$.

The way a family is asked for autopsy consent goes a long way in determining if consent will be granted or not [5]. If the clinician is uncomfortable and illinformed, it is likely that this will be communicated to the family, who, in turn, will be less likely to consent to the autopsy [5].

The pathologists are not completely free of blame for the declining autopsy rates. At times, they may not be as prompt as expected by both the clinicians and the bereaved families [34]. It is important to perform autopsies as a matter of urgency soon after death. This may not be possible within the current constraints on staffing and pathology services in most African countries [34].
Health funding agencies have also played a role in the declining autopsy rate. Funding agencies and governments have consistently not recognised the importance of serious investment into pathology and autopsy studies [39].

In resource-limited settings like ours, with limited availability and application of sophisticated diagnostic techniques, the value and utility of autopsies are paramount [9]. Therefore to stem the decline in paediatric autopsy rates, our suggestions include, staff training in counseling and communication skills for requesting an autopsy examination (this is particularly important because the staff members must fully consider local beliefs, social and religious values and customs [34]); death certificates should not be issued immediately after death, until an autopsy is done; the hospital should make and enforce policies that mandate the performance of autopsies on all paediatric coroner's cases; and pathologists should endeavor to perform post mortem examinations as soon as possible following death. The limitations of the study included incorrect or missing data.

\section{Conclusion}

Despite the importance, paediatric autopsies are not routinely performed in this centre, and in many others. Indeed, paediatric autopsy rates have declined globally. This should not be the case. Paediatric autopsy rates can be improved by making consistent autopsy requests by the attending clinicians. Advocacy and enlightenment campaigns should be conducted at facility and community levels to educate everyone concerned about the benefits of paediatric autopsies.

Permission from IRB: Yes

Funding: No funding sources.

Conflict of Interest: The authors declare no conflict of interest.

\section{References}

1. Kotabagi RB, Charati SC, Jayachandar D. Clinical autopsy vs medicolegal autopsy. Med J Armed Forces India 2005;61:258-263. Available online: http://medind.nic.in/maa/t05/i3/maat05i3p258.pdf.

Accessed: 24. July. 2015.

2. Law M, Stromberg P, Meuten D, Cullen J. Necropsy or Autopsy? It's All About Communication! Veterinary Pathology 2012; 49(2): 271-272. DOI: $10.1177 / 0300985811410722$ 
3. Kaschula ROC. The Pediatric Autopsy in Africa. Arch Pathol Lab Med 2013; 137 (6): 756-766; Available online: http://www.archivesofpathology.org/doi/pdf/10.5858/ar pa.2011-0589-RA. Accessed: 26. July. 2015. DOI: 10.5858/arpa.2011-0589-RA.

4. Kumar P, Taxy J, Angst DB, Mangurten HH. Autopsies in children: are they still useful? Arch Pediatr Adolesc Med 1998 Jun;152(6):558- 63. Available online:

http://archpedi.jamanetwork.com/article.aspx?articleid= 189612. Accessed: 25. July. 2015. DOI: 10.1001/archpedi.152.6.558.

5. Ekanem VJ, Vhriterhire CO. Relevance of clinical autopsy in medical practice in Sub? Saharan Africa. Sahel Medical Journal 2015 Apr-Jun; 18 (2): 49-56. Available online: http://www.smjonline.org/temp/SahelMedJ18249539545_145914.pdf . Accessed: 25. July. 2015. DOI: 10.4103/1118-8561.160795.

6. Cox JA, Lukande RL, Lucas S, Nelson AM, Van Marck E, Colebunders R. Autopsy Causes of Death in HIV-Positive Individuals in Sub-Saharan Africa and Correlation with Clinical Diagnoses. AIDS Rev. 2010 Oct-Dec;12(4):183-94. Available online: http://www.aidsreviews.com/files/2010_12_4_183194.pdf. Accessed: 23. July. 2015.

7. Cox JA, Lukande RL, Kateregga A, Mayanja-Kizza H, Manabe YC, Colebunders R. Autopsy acceptance rate and reasons for decline in Mulago Hospital, Kampala, Uganda. Trop Med Int Health 2011 Aug; 16 (8): 1015 - $18 . \quad$ Available online: http://onlinelibrary.wiley.com/doi/10.1111/j.13653156.2011.02798.x/epdf . Accessed: 23. July. 2015. DOI:10.1111/j.1365-3156.2011.02798.x.

8. Lishimpi K, Chintu C, Lucas S, Mudenda V, Kaluwaji J, Story A, Maswahu D, Bhat G, Nunn AJ, Zumla A. Necropsies in African children: consent dilemmas for parents and guardians. Arch Dis Child 2001;84:463-67. Available online: http://adc.bmj.com/content/84/6/463.full.pdf. Accessed: 23. July. 2015.

9. Tette E, Yawson AE, Tettey Y. Clinical utility and impact of autopsies on clinical practice among doctors in a large teaching hospital in Ghana. Glob Health Action 2014; $\quad 7$ : 23132 http://dx.doi.org/10.3402/gha.v7.23132. Available online:

http://www.ncbi.nlm.nih.gov/pmc/articles/PMC391402

9/pdf/GHA-7-23132.pdf. Accessed: 20. July. 2015.

10. Yawson AE, Tette E, Tettey Y. Through the lens of the clinician: autopsy services and utilization in a large teaching hospital in Ghana. BMC Research Notes 2014; 7:943:1-6. Available online: http://www.ncbi.nlm.nih.gov/pmc/articles/PMC430763 8/pdf/13104_2014_Article_3450.pdf. Accessed: 25. July. 2015. DOI: 10.1186/1756-0500-7-943.

11. Burton JL. The history of the autopsy. In Burton JL and Rutty GN(eds): The Hospital Autopsy. 3rd Ed. Hodder Arnold London 2010:1 - 10.

12. Gordijn SJ, Erwich JJ, Khong TY. Value of the perinatal autopsy: critique. Pediatr Dev Pathol. 2002 Sep - Oct;5(5):480-8. Accessed: 24. July. 2015. DOI: 10.1007/s 10024-002-0008-y.

13. Feinstein JA, Ernst LM, Ganesh J, Feudtner C. What New Information Pediatric Autopsies Can Provide: A Retrospective Evaluation of 100 Consecutive Autopsies Using Family-Centered Criteria. Arch Pediatr Adolesc Med. 2007 Dec;161(12):1190-6. Accessed: $22 . \quad$ July. 2015. DOI:10.1001/archpedi.161.12.1190.

14. Lundberg GD. Low-Tech Autopsies in the Era of High-Tech Medicine: Continued Value for Quality Assurance and Patient Safety. JAMA 1998 Oct 14; 280(14): 1273 - 4. Accessed: 22. July. 2015. DOI: doi:10.1001/jama.280.14.1273.

15. Peres LC. Review of pediatric autopsies performed at a university hospital in Ribeirão Preto, Brazil. Arch Pathol Lab Med 2006 Jan;130(1):62-8. Available online:

http://www.archivesofpathology.org/doi/pdf/10.1043/15 43-

2165\%282006\%29130\%5B62\%3AROPAPA\%5D2.0.C O\%3B2. Accessed: 26. July. 2015.

16. Khong TY. A review of perinatal autopsy rates worldwide, 1960s to 1990s. Paediatr Perinat Epidemiol 1996 Jan;10:97-105. Accessed: 22. July. 2015. DOI: $10.1111 /$ j.1365-3016.1996.tb00030.x.

17. World Health Organization. Health and the Millennium Development Goals. Geneva: World Health Organization 2005: 82. 
18. Adappa R, Paranjothy S, Roberts Z, Cartlidge PH. Perinatal and infant autopsy. Arch Dis Child Fetal Neonatal Ed 2007 Jan;92:F49-50. Available online: http://www.ncbi.nlm.nih.gov/pmc/articles/PMC267531 3/pdf/F49.pdf. Accessed: 22.July.2015. DOI: 10.1136/adc.2005.091447.

19. Scottish Programme for Clinical Effectiveness in Reproductive Health. Scottish Perinatal and Infant Mortality and Morbidity Report 2001. Edinburgh: SPCERH; 2002: 80.

20. Brodlie M, Laing IA, Keeling JW, McKenzie KJ. Ten years of neonatal autopsies in tertiary referral centre: retrospective study. BMJ. 2002 Mar 30;324(7340):761-3. Available online: http://www.ncbi.nlm.nih.gov/pmc/articles/PMC100315/ pdf/761.pdf. Accessed: 22.July.2015.

21. Turnbull A, Osborn M, Nicholas N. Hospital autopsy: Endangered or extinct? J Clin Pathol 2015;0:1-4. Available online: http://jcp.bmj.com/content/early/2015/05/08/jclinpath2014-202700.full.pdf+html. Accessed: 31. July. 2015. DOI:10.1136/jclinpath-2014-202700.

22. Korle-Bu Teaching Hospital . Annual report 2010 , Accra, Ghana: Korle - Bu Teaching Hospital. Korle-Bu Teaching Hospital, 2011.

23. Gohill R, Nkanza NK, Bhagwandeen SB, Naik KG. A review of autopsies at the University Teaching Hospital, Lusaka, 1975. Med J Zambia. 1979 AprMay;13(2):28-32. PMID: 263368. Accessed: 26. July. 2015.

24. Eke FU, Frank-Briggs A, Ottor J. Childhood Mortality In Port Harcourt, Nigeria. Anil Aggrawal's Internet Journal of Forensic Medicine and Toxicology, 2001; Vol. 2, No. 2 (July-Dec 2001): Available online: http://www.anilaggrawal.com/ij/vol_002_no_002/paper s/paper003.html. Accessed: 20. July. 2015.

25. Nwafor CC, Abali C, Nnoli MA. Childhood Mortality in Federal Medical Centre Umuahia, South Eastern Nigeria. Oman Med J. 2014 Sep; 29(5):320-4. Accessed: 22. July. 2015. DOI: 10.5001/omj.2014.87.

26. Ugiagbe EE, Osifo OD. Postmortem examinations on deceased neonates: A rarely utilized procedure in an African referral center. Pediatr Dev Pathol 2012 Jan-
Feb;15:1-4. Accessed: 22. July.2015. DOI: http://dx.doi.org/10.2350/10-12-0952-OA.1.

27. Akang EE, Asinobi AO, Fatunde OJ, Pindiga HU, Okpala JU Abiola AO, et al. Childhood mortality in Ibadan: An autopsy study. Niger J Paediatr 1992;19:30-6.

28. Ayoola OO, Orimadegun AE, Akinsola AK, Osinusi K. A five-year review of childhood mortality at the University College Hospital, Ibadan. West Afr J Med. 2005 Apr-Jun;24(2):175-9.

29. Oluwasola AO, Fawole OI, Otegbayo JA, Ayede IA, Ogun GO, Ukah CO, Bamigboye AE. Trends in clinical autopsy rate in a Nigerian tertiary hospital. Afr J Med Med Sci. 2007 Sep; 36(3):267-72. PMID: 18390067. Accessed: 26. July. 2015.

30. Abdulkareem FB, Elesha SO, Banjo AA. Prospective autopsy study of childhood mortality in Lagos, Nigeria (1993-1994). Nig Qt J Hosp Med. 1996;6:88-95.

31. Ekanem VJ, Gerry IE. Attitude of Nigerian resident doctors towards clinical autopsy. Niger Postgrad Med J. 2007 Mar;14(1):8-11.

32. Rosenbaum GE, Burns J, Johnson J, Mitchell C, Robinson M, Truog RD. Autopsy consent practice at US teaching hospitals: results of a national survey. Arch Intern Med. 2000 Feb 14;160(3):374-80. Accessed: 22. July.2015. DOI:10.1001/archinte.160.3.374.

33. Start RD, Brain SG, McCulloch TA, Angel CA. Analysis of necropsy requests behaviour of clinicians. J Clin Pathol 1996; 49: 29-33. Available online : http://jcp.bmj.com/content/49/1/29.full.pdf. Accessed 31. July. 2015.

34. Mudenda V, Lucas S, Shibemba A, O'Grady J, Bates M, Kapata N, Schwank S, Mwaba P, Atun R, Hoelscher M, Maeurer M, Zumla A. Tuberculosis and Tuberculosis/HIV/AIDS-Associated Mortality in Africa: The Urgent Need to Expand and Invest in Routine and Research Autopsies. J Infect Dis. 2012; S1S7. Available online : http://jid.oxfordjournals.org/content/early/2012/03/21/in fdis.jir859.full.pdf+html. Accessed 31. July. 2015. DOI: 10.1093/infdis/jir859. 
35. Mittleman RE, Davis JH, Kasztl W, Graves WM Jr. Practical approach to investigative ethics and religious objections to the autopsy. J Forensic Sci. 1992 May;37(3):824-9.

36. Gatrad AR. Muslim customs surrounding death, bereavement, postmortem examinations, and organ transplants. BMJ. 1994;309:521-523. Accessed: 31. July. 2015.2 DOI: http://dx.doi.org/10.1136/bmj.309.6953.521.

37. Rispler-Chaim V. The ethics of postmortem examinations in contemporary Islam. J Med Ethics 1993;19:164-8.
38. Charlton R. Autopsy and medical education: a review. J R Soc Med 1994; 87: 232-236. Available online:

http://jme.bmj.com/content/19/3/164.full.pdf+html Accessed: 31. July.2015. doi:10.1136/jme.19.3.164.

39. Zumla A, Huggett J, Dheda K, Green C, Kapata N, Mwaba P. Trials and tribulations of an African-led research and capacity development programme: the case for EDCTP investments. Trop Med Int Health. 2010 Apr;15(4):489-94. Accessed: 30.July.2015. DOI: 10.1111/j.1365-3156.2010.02479.x.

\section{How to cite this article?}

IJEZIE, Echey, OKPOKOWURUK, Frances Sam, NWAFOR, Chukwuemeka Charles. Pediatric death audit with special emphasis on autopsy at the University of Uyo Teaching Hospital, Uyo, Nigeria: a 6-year review. Pediatr Rev: Int J Pediatr Res 2015;2(4):52-59.doi:10.17511/ijpr.2015.i04.04 